\title{
Las Fuerzas Militares colombianas durante el Frente Nacional: autonomía en el manejo de la seguridad ${ }^{1}$
}

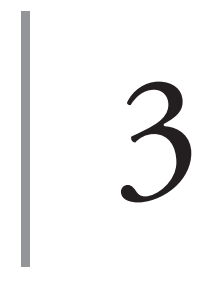

https://doi.org/10.21830/9789585318380.03

Carlos Daniel Chaves Avellaneda ${ }^{2}$

Fundación Universitaria del Área Andina

\section{Resumen}

Este capítulo expone las principales características que determinaron el papel de las Fuerzas Militares colombianas durante en el periodo del "Frente Nacional". Se expondrán las condiciones políticas internas que llevaron a los militares a aceptar de forma parcial el predominio de las instituciones civiles, así como las razones que sirvieron al sector castrense para contar con una autonomía en el manejo del orden público y la lucha contra las guerrillas, a través de políticas como el estado de sitio y la Doctrina de la Seguridad Nacional. Autonomía que mantuvieron aún después de los dieciséis años del Frente Nacional y que se reflejó en los principales planes y operativos antisubversivos.

Palabras clave: conflicto armado; Frente Nacional; seguridad nacional; Fuerzas Armadas; guerrillas; Colombia.

1 Este capítulo hace parte de los resultados del proyecto de investigación "Relaciones civiles-militares en Colombia: una aproximación a los roles de las Fuerzas Militares" del Grupo de Investigación en Ciencias Militares de la Escuela Militar de Cadetes "General José María Córdova" categorizado en B por Minciencias y con código de registro COL0082556. Los puntos de vista y los resultados de este artículo pertenecen al autor y no reflejan necesariamente los de las instituciones participantes.

2 Historiador (Pontificia Universidad Javeriana). Magíster en Análisis de Problemas Políticos Económicos e Internacionales Contemporáneos (Academia San Carlos-Universidad Externado de Colombia). Profesional en Ciencias de la Información (Uniquindío). Especialista en Estadística Aplicada (Los Libertadores). Profesor Facultad de Derecho en la Fundación Universitaria del Área Andina. Investigador senior en el Centro Libertad y Pensamiento Otto Morales Benítez (Centotto). ORCID: https://orcid.org/0000-0002-2726-4212 - Contacto: cchaves7@areandina.edu.co 


\section{Introducción}

En este capítulo se exponen las relaciones entre las instituciones civiles y los militares en el periodo de la historia colombiana conocido como Frente Nacional. Para entender estas relaciones se parte de la hipótesis según la cual los militares se encontraron en una condición dual, en la que simultáneamente respetaron la institucionalidad y el mandato de los civiles, pero, a la vez, contaron con libertad para el diseño de las estrategias de manejo del orden público. ¿Cómo se llegó a esta situación dual de sometimiento y autonomía? Intentar dar respuesta a interrogante es el objetivo central de este escrito.

Este análisis se estructura a través de la exposición de los factores internos y externos que influyeron sobre el accionar de las Fuerzas Militares. En un primer apartado se abordará el acuerdo político y la repartición burocrática del poder que hubo mientras se mantuvo el Frente Nacional. Posteriormente, se analizarán los efectos de la aplicación de la figura del estado de sitio, que llevó a que el Ejecutivo contase con poderes extraordinarios y sin contrapeso alguno, lo que le permitió ampliar las atribuciones y las funciones de los militares, los cuales, cabe anotar, se mantuvieron en operación constante, como se mostrará en un tercer apartado. Esas operaciones se sostuvieron contra las organizaciones guerrilleras de primera generación, cuya aparición, origen y situación durante el Frente Nacional es explicada en un cuarto lugar. Teniendo en cuenta este marco, se expondrán las dos décadas claves del Frente Nacional: la década de los sesenta en la que los militares se adaptaron y aceptaron el régimen bipartidista, y, finalmente, la de los setenta, cuando los militares establecen la Doctrina de la Seguridad Nacional como su pensamiento guía. En el apartado final se compararán dos de las principales estrategias de seguridad creadas en este periodo: el Plan Lazo y el Estatuto de Seguridad, teniendo en cuenta sus principales características. De esta manera, se ilustrará el desarrollo histórico de las relaciones entre civiles y militares, sobre las cuales se ha mantenido una controversia hasta el día de hoy.

\section{La dinámica política del Frente Nacional}

Para analizar la situación de los militares colombianos en las décadas de los sesenta y setenta, el presente escrito los considerará a partir la tesis de Max 
Weber, según la cual las Fuerzas Armadas en representación del Estado son quienes detentan el monopolio de la coacción física legitima, es decir, del uso la violencia como recurso para mantener el orden. Al estar las Fuerzas Militares sujetas a la ideología y defensa del Estado, la historia de cualquier Ejército debe construirse teniendo en consideración el sistema de relaciones políticas y sociales que caracterizan al Estado en un momento determinado específico (Weber, 1964, pp. 1056-1057), para el caso de este estudio el periodo analizado es el del Frente Nacional.

Tras la caída del Dictador Gustavo Rojas Pinilla, en 1957, se estableció en Colombia un sistema político bipartidista conocido como Frente Nacional, el cual fue aprobado por la ciudadanía en un plebiscito efectuado el 1 de diciembre de 1957. Este sistema se sustentaba en la alternación del gobierno de los dos principales partidos, el Liberal y el Conservador durante un periodo de dieciséis años, a partir de 1958. De esta forma, las dos colectividades acordaron compartir el poder aplicando una repartición paritaria de los cargos públicos.

Ha habido dos visiones frente a la dinámica política del Frente Nacional. Para analistas como Jonathan Hartlyn (1993, pp. 26-27), el Frente Nacional era un mecanismo restrictivo de la democracia en el que las dos colectividades principales políticas aseguraron su poder, en desmedro de otros sectores. Esta restricción obedecía al temor que tenían las élites de perder su posición dominante por un recrudecimiento de la violencia en los campos. Sin embargo, como señala Javier Ocampo López (1993, pp. 33), el Frente Nacional fue un "sistema bipartidista controlado, con un tipo de democracia interna, cuyas disputas se dirimían en busca de concordancias dentro de los partidos tradicionales. Era indispensable para liquidar la Violencia y reconstruir el Estado de Derecho, que había desaparecido”. Al margen de estas dos visiones sobre el Frente Nacional como sistema de gobierno, esta búsqueda de consenso bipartidista influyó sobre la estructura y los planteamientos de las Fuerzas Militares en aquel entonces. Cabe anotar que esta influencia perduraría hasta después de los dos gobiernos que siguieron al periodo de la alternación: el de Alfonso López Michelsen y el de Julio César Turbay Ayala, incluso algunos analistas consideran que el sistema político terminó imperando hasta la reforma constitucional de 1991. 


\section{La política de estado de sitio}

Un factor que permitió la autonomía militar fue la puesta en práctica del estado de sitio. Esta era una facultad presidencial establecida en el artículo 121 de la Constitución, para declarar que había perturbaciones en el orden público de manera parcial o total en el país. Una vez era proclamado, el estado de sitio aumentaba los poderes del Ejecutivo, el cual obtenía tales atribuciones con el objeto de restaurar el orden público. Los cuatro presidentes del Frente Nacional $^{3}$ y los cuatro siguientes ${ }^{4}$ gobernaron haciendo uso recurrente de esta facultad, la cual, tras su aprobación, permitió al presidente y sus ministros expedir todas las normas que consideraron necesarias para restaurar el orden. De igual manera, el poder Ejecutivo podía suspender las leyes que fuesen aparentemente incompatibles con el estado de sitio. Para Adolfo Salamanca y José Luis Aramburo (1981, pp. 22-32), el estado de sitio se convirtió en una herramienta que, aunque en teoría buscaba el bienestar general, en la práctica tenía un único beneficiario: el presidente de la república, ya que podía gobernar a través de la expedición de decretos y tomar medidas económicas y políticas sin tener en cuenta al Congreso ni al Poder Judicial.

El problema de la aplicación del estado de sitio, según autores como Gustavo Gallón (1979, pp. 13-16), radicaba en la vaguedad del concepto "perturbación del orden público", pues este era de libre interpretación por parte del Gobierno central, por lo que cualquier situación de desorden social podía ser considerada como razón suficiente para invocar el estado de sitio. De esta manera, una acción armada de las guerrillas podría ser considerada a la par de una manifestación estudiantil. De este modo, dos acciones aparentemente distintas podían ser consideradas como problemas de seguridad, por lo que se podía ejercer la fuerza contra las mismas. Así, el Ejecutivo podía ordenar acciones como arrestar sospechosos, expropiar bienes y censurar a la prensa.

3 Alberto Lleras Camargo, del Partido Liberal (1958-1962); Guillermo León Valencia, del Partido Conservador (1962-1966); Carlos Lleras Restrepo, del Partido Liberal (1966-1970); y Misael Pastrana Borrero, del Partido Conservador (1970-1974).

4 Alfonso López Michelsen (1974-1978), Julio César Turbay Ayala (1978-1982), Belisario Betancur (1982-1986) y Virgilio Barco (1986-1990). Todos ellos, salvo Belisario Betancur, fueron avalados por el Partido Liberal. 
Por tales razones, se puede considerar que el verdadero objetivo del estado de sitio era combatir las formas de oposición y la movilización de las clases populares, con el pretexto de defender a las instituciones. Por tanto, el estado de sitio permitía que los sectores de oposición fuesen considerados como subversivos, o incluso como amenazas a la existencia misma de la sociedad, con lo que su discurso y reclamaciones perdían legitimidad. Así, durante la vigencia del estado de sitio las Fuerzas Armadas acrecentaban su poder y autonomía, ya que eran las llamadas a defender el orden legítimo del Estado. En tal sentido, los militares tuvieron una ampliación de sus competencias pudiendo juzgar civiles, con el pretexto de garantizar la seguridad (Gallón, 1979, pp. 123-126).

La aplicación del estado de sitio en Colombia generaba una confusión en las funciones de la Policía y los militares, ya que al quedar en manos de estos últimos el manejo del orden público, contaban con una especie de derecho a ejercer acciones represivas, en aras de obtener la victoria contra los enemigos del Estado. Como señala Iván Orozco Abad (1992, pp. 191-192), existen dos clases de estado de sitio, por un lado el estado de sitio militar-político, el cual está pensado para situación de guerra y/o conflicto armado, en él se reconoce una cierta "simetría" en las relaciones entre el Estado y los alzados en armas contra este; al existir dicha simetría, que implica la imposibilidad de derrota de cualquiera de los bandos, ambos actores, rebeldes y Estado, deben negociar entre sí como alternativa para solucionar el conflicto.

Sin embargo, en Colombia ha imperado el estado de sitio policivo-punitivo, en el cual el Estado determina que no hay problema alguno y que el país vive una situación de paz, la cual corre el riesgo de ser perturbada por una serie de amenazas que deben ser combatidas por la fuerza. En vigencia de este tipo de estado de sitio se permite a los gobernantes suspender las libertades y garantías constitucionales de los ciudadanos, con el fin de obtener herramientas para luchar contra tales amenazas, por lo cual se puede recurrir a todo tipo de arbitrariedades para obtener la victoria (Orozco, 1992, pp. 196-197). Puede afirmarse que, en Colombia, el estado de sitio se utilizó para cambiar la visión del derecho civil interno y convertir a los combatientes rebeldes o delincuentes políticos en terroristas, contra los cuales se debía luchar por todos los medios, aun cuando esto implicase pasar por encima de la Constitución. 


\section{Unas Fuerzas Armadas autónomas y en actividad constante}

Distintas coyunturas históricas han llevado a que desde los años cincuenta hasta nuestros días, las Fuerzas Armadas se encuentren en operaciones permanentes, las cuales continuaron durante el Frente Nacional (Rouquié, 1984, p. 233). Esto se debe a que la consolidación del pacto bipartidista coincidió con la aparición de organizaciones guerrilleras que encontraron en la Revolución cubana de 1959 una inspiración para intentar la toma del poder a través de tácticas y estrategias de guerra irregular. El discurso político de las guerrillas se basaba en la afirmación de que el Frente Nacional había bloqueado la posibilidad de que otros grupos políticos distintos a los partidos tradicionales pudiesen ejercer los cargos públicos. Se debe considerar que, a través de los distintos gobiernos del Frente Nacional, el Estado mantuvo una lucha contra estos grupos armados irregulares, en algunos periodos con mayor intensidad que en otros. Tanto las organizaciones guerrilleras de primera generación (las Fuerzas Armadas Revolucionarias de Colombia (FARC), el Ejército de Liberación Nacional (ELN) y el Ejército Popular de Liberación (EPL) que aparecieron en la década de los sesenta), como las de segunda generación (el M-19, el Movimiento de Autodefensa Obrera (ADO) y el Partido Revolucionario de los Trabajadores (PRT), surgidos en la década de los setenta), fueron enfrentadas con la lógica de que constituían un enemigo que debía ser combatido en todos sus frentes, tanto el militar como el político, siguiendo el ejemplo de los regímenes militares del Cono Sur.

De igual manera, las Fuerzas Militares colombianas tuvieron un desarrollo histórico distinto al de otros países de Latinoamérica. Mientras en esas mismas décadas las Fuerzas Militares de varios países latinoamericanos habían llegado a hacerse con el control total del Estado, en Colombia se mantuvo el sistema democrático, lo que no implicó que los militares viesen disminuido su poder e injerencia en el Estado, como se explicará más adelante.

De esta manera, el Estado colombiano cabe dentro de la categoría de Estados latinoamericanos excepcionales, que analistas como Alain Rouquié y Frank Saffern denominan "Estados Civiles”. Por medio de esta categoría, los 
autores estudian a las naciones latinoamericanas donde las Fuerzas Militares no llegaron a convertirse en el Gobierno y en las que prevaleció el dominio de las instituciones civiles, como México, Colombia, Costa Rica y Venezuela. Aun así, los autores afirman que algunas de estas naciones no podrían ser verdaderos ejemplos de "instituciones democráticas", los autores, en cambio, reconocen que los militares de estos países no tuvieron éxito en los intentos de tipo golpista, por lo que en tales Estados prevalecieron las instituciones de la democracia representativa (Rouquié \& Saffern, 1997, p. 312).

En el caso colombiano, se pueden destacar tres factores particulares que llevaron a que las Fuerzas Militares colombianas no obstaculizasen la prevalencia de los poderes civiles. En primer lugar, las Fuerzas Armadas han sido, por tradición, carentes de prestigio; en segundo término, los militares colombianos tuvieron una tardía profesionalización con respecto a otros países; $\mathrm{y}$, como un tercer factor, y quizá el más importante, como se ha señalado ya, el Ejército de Colombia se ha encontrado en permanente operación desde los tiempos del periodo histórico nacional conocido como "La Violencia" (Rouquié \& Saffern, 1997, pp. 317-318).

En este último aspecto, cabe señalar que el hecho de permanecer en actividad permanente trajo consigo una división y dispersión de las Fuerzas Militares durante su lucha contra los grupos irregulares, por lo cual estas no han sido proclives a los golpes de Estado. Sin embargo, los militares colombianos desarrollaron una función de legitimadores del sistema bipartidista, formando una especie de acuerdo implícito con los políticos de turno. En dicho convenio, los militares optaron por no intervenir en la vida política y limitar sus funciones al manejo del orden público; sin embargo, a cambio de esta posición, los militares ganaron una autonomía en el manejo de sus operaciones.

Se debe tener en cuenta que el Ejército colombiano fue, desde principios del siglo XX, muy cercano al Partido Conservador, colectividad en torno a la cual se creó como institución profesionalizada. Durante "La Violencia", el Ejército apoyó al gobierno de Laureano Gómez e impuso por la fuerza el orden en varias regiones apartadas. Este apoyo del Ejército al conservatismo contrastaba con la actitud asumida por el sector castrense hacia los presidentes liberales, quienes fueron vistos con recelo, ya que estos apoyaban a la Policía 
en aras de hacer contrapeso al Ejército por su fuerte ideología conservadora. Esta actitud fortaleció los lazos entre los militares y los conservadores, lo que se consolidaría aún más con el Frente Nacional, al tener mayor cercanía por su trabajo conjunto con los gobiernos de dicha ala política (Rouquié, 1984, pp. 234-235).

Por tanto, aunque las Fuerzas Militares en Colombia no llegaron a convertirse en el gobierno, estas gozaron de una presencia en el Estado que les permitió ganar una relativa independencia en el manejo del orden público. Por tanto, se puede afirmar que en el sector castrense existió una autonomía militar relativa, condición que se fue configurando de manera paralela al Frente Nacional.

El desarrollo histórico de la autonomía militar en Colombia podría explicarse en dos fases, una primera en la década de los sesenta, donde las Fuerzas Militares se adaptaron al Sistema Político imperante durante el Frente Nacional; y una segunda fase en la década de los setenta, en la que tuvo una clara influencia la Doctrina de la Seguridad Nacional. Sin embargo, no se puede desconocer que, en ambas etapas, hubo un importante factor de la legislación colombiana que posibilitó la condición de la autonomía: la política del estado de sitio, herramienta legal por medio de la cual, a pesar de que los civiles gobernaban, los militares ganaban libertad para tomar las medidas que considerasen pertinentes.

\section{Las guerrillas, un nuevo actor político}

Se debe tomar en cuenta que, en esta misma década, de forma simultánea a la consolidación del Frente Nacional, surgió la primera generación grupos guerrilleros, las FARC, el ELN y el EPL, los cuales centraron su acción en las zonas rurales. Posteriormente, en la década de los setenta, surgieron grupos como el M-19, el ADO, el Movimiento de Izquierda Revolucionaria (MIR) y el PRT que tenían un enfoque mucho más urbano y optaban por acciones en las grandes ciudades. En este apartado se expondrá cómo se llevó a cabo el surgimiento y la consolidación de los principales grupos armados que emergieron en la época del Frente Nacional: las FARC, el (ELN) y el EPL. 
El ELN inició sus acciones en las selvas de la zona sur occidental de Santander, su ideología estaba marcada por el guevarismo y contó inicialmente con el respaldo de Cuba. Los territorios santandereanos estuvieron marcados por constante activismo y movilización política armada, allí se llevó a cabo buena parte de la Guerra de los Mil Días, y allí también hubo levantamientos ciudadanos tras la muerte de Jorge Eliécer Gaitán. De ahí que se considerase un territorio estratégico para dar inicio a la rebelión guerrillera, la cual fue iniciada por un grupo de jóvenes becarios en Cuba, quienes recibieron adoctrinamiento y buscaron emular en Colombia la estrategia del "foco guerrillero" propuesto por el Che Guevara y Regis Debray (Pizarro, 2004, pp. 100-101). Cabe anotar que estos jóvenes optaron por una acción más radical, dado que consideraban demasiado pasivo al Partido Comunista (Palacios, 2012, pp. 83-85).

$\mathrm{Su}$ base estuvo formada inicialmente por trabajadores y universitarios santandereanos, si bien se unieron posteriormente líderes estudiantiles de otras ciudades, esta guerrilla no realizó trabajos de politización sobre la población campesina, de la cual siempre desconfiaron. En el ELN siempre hubo prioridad de la acción armada por encima de la política, estrategia que fue más notable cuando perdió el apoyo cubano. Esto llevó a conflictos internos en la guerrilla que la debilitaron (Pécaut, 1989, p. 311), tal situación fue aprovechada por las Fuerzas Armadas que llevaron a cabo operativos que diezmaron al ELN, pues en algunos de ellos perdió a sus líderes, como el sacerdote Camilo Torres, en 1966, y en otros, como sucedió en la "Operación Anorî" de 1973, se debilitó su poder en Antioquia, donde se habían insertado a principios de 1970. Estos problemas llevaron a que los distintos grupos de esta guerrilla se replegasen hacia regiones más apartadas, como Arauca, donde empezaron a extorsionar a compañías petroleras, que les darían recursos por medio de los cuales pudieron retomar la ofensiva en la década de los ochenta (Palacios, 2000, pp. 265-266).

Por su parte, el EPL, cuya estrategia militar fue similar a la del ELN pero cuya ideología era Maoísta, pretendía repetir la estrategia del "Ejército Rojo" en China, pero en la práctica terminó valiéndose de la estrategia del foco. Esta organización encontró su base social en campesinos y trabajadores bananeros del Urabá antioqueño (Palacios, 2000, p. 264). Sin embargo, igual que 
el ELN, este grupo fue diezmado por las luchas ideológicas internas, en especial por los reiterados conflictos que sostenían con las tendencias comunistas, mucho más cercanas a la Unión Soviética que al modelo chino. A estas estas disputas internas se sumaron poderosos cercos militares realizados entre 1967 y 1969 (Pizarro, 1989, p. 251). Lo que llevó a que el EPL optase por la acción en los núcleos urbanos.

Ha habido una amplia discusión sobre el origen de las FARC, para analistas como Eduardo Pizarro (2004, p. 85) esta guerrilla tiene su origen en los grupos de autodefensa campesina, que fueron apoyados por el Partido Comunista Colombiano, en respuesta al accionar represivo desatado desde 1946. Como señala Alfredo Molano (2014), tras esta persecución, estos grupos iniciaron una serie de colonizaciones armadas en las regiones de El Pato, Guayabero y Ariari. Estos grupos quedaron activos después de la caída de la dictadura de Rojas Pinilla. Tras el establecimiento del Frente Nacional, se buscó la reintegración de estos grupos por medio de programas de rehabilitación impulsados por la Administración de Lleras Camargo, que pretendían mejorar las condiciones de los territorios. Finalmente, aunque los grupos de autodefensa no se desarmaron, optaron por la vía política y pretendieron convertirse en un movimiento agrarista, que no logró consolidar capacidad de poder.

Sin embargo, con la llegada del gobierno de Guillermo León Valencia, las cosas cambiaron, pues simultáneamente el líder conservador Álvaro Gómez Hurtado asumió una retórica reaccionaria, en la que afirmaba que en algunos territorios del país se habían creado unas "repúblicas independientes al servicio del comunismo internacional”. Dichas repúblicas, que escapaban al control del Estado, según Gómez, se encontrarían ubicadas precisamente en terrenos de Marquetalia, Riochiquito, El Pato, Guayabero, Sumapaz y el Ariari. El presidente Valencia sucumbió ante la presión del alvarismo y optó por iniciar una operación militar, con el fin de llevar a cabo una guerra de exterminio contra estos enclaves comunistas. Como se señaló, estos grupos funcionaban, en principio, bajo la lógica de la "autodefensa", es decir, como grupos que tenían, según Jaime Guaracas, "la misión de estar patrullando, previendo cualquier peligro para trabajar más tranquilo" (Molano, 2014), sin que se efectuaran ataques contra la Fuerza Pública. 
De esta manera, en mayo de 1964, se inició un asalto a gran escala sobre Marquetalia, desplegado con todo el potencial del Ejército colombiano. Como consecuencia de esta acción, el Partido Comunista Colombiano continuó ejerciendo una influencia sobre estos grupos, los cuales se reorganizaron y pasaron de ser grupos de autodefensa a guerrillas móviles, las cuales se unieron en un grupo al que inicialmente denominaron "Bloque Sur", para posteriormente adoptar el nombre de Fuerzas Armadas Revolucionarias de Colombia-FARC, que tras su repliegue en la década de los ochenta optarían por el camino de la acción ofensiva contra el Estado.

\section{Los sesenta: los militares defienden al Frente Nacional}

Para explicar esta primera fase del desarrollo de la autonomía militar es pertinente resaltar que hubo una aceptación tácita, por parte de los militares, del sistema político, lo que contrastaba con los años de La Violencia, en los que los militares eran leales a uno u otro partido, según sus conveniencias. Así, los militares optaron por reconocer y aceptar el sistema bipartidista, y consideraron que su función consistía en defender dicho sistema.

Gustavo Gallón (1983, pp. 16-38) afirma que la adaptación de los militares al sistema bipartidista fue la condición que les permitió ganar poder y les dio la posibilidad de ejercer nuevas funciones, además de la seguridad fronteriza y la defensa de la nación, funciones habituales de los Ejércitos. En tal sentido, para garantizar la independencia de las Fuerzas Armadas, los partidos políticos entregaron el manejo el Ministerio de Guerra (ahora de Defensa) a los militares. El control del Ministerio permitió que se diera un giro en las funciones del Ejército y la Policía, pues el "manejo del orden público" era un asunto que tradicionalmente había estado a cargo de esta última, pero en la década de los sesenta esta función pasó a manos de los militares, que comenzaron a ejercer actividades que implicaban el control de la población. Esta ampliación de las funciones del sector castrense implicó que los demás estamentos de la Fuerza Pública quedasen sometidos al Ejército. 
Por tanto, como señala Francisco Leal Buitrago (1994, p. 70) existió una subordinación de los militares, no a los partidos políticos sino al Estado y al conjunto de sus instituciones, sin importar la colectividad que se encontrase en el poder. Sin embargo, esta subordinación llevó a un desentendimiento por parte de las autoridades civiles con respecto al diseño de las estrategias de seguridad y defensa, quedando estas últimas, de manera exclusiva, en manos de las Fuerzas Militares.

Ese desinterés por parte de las instituciones civiles con respecto a los problemas de seguridad llevó a que en las Fuerzas Armadas surgiera la idea de defender al Estado, iniciativa que se hizo extensiva al hecho de que los posibles espacios críticos al Gobierno, como huelgas o movilizaciones políticas, fuesen percibidas como problemas de orden público que debían ser enfrentados por la vía militar. De esta manera, las instituciones civiles, que en algunas ocasiones se mostraron incapaces de resolver problemas políticos y sociales, optaron por llamar al Ejército en defensa de la institucionalidad, sin importar que este incurriera en acciones de orden represivo (Blair, 1993, pp. 91-92). Es más, la confianza del Estado en el manejo militar para la solución de problemas sociales permitió que la autonomía militar se viese acrecentada.

Aun así, aunque las Fuerzas Militares de la década de los sesenta vieron aumentado su poder, el Estado impuso un límite a las opiniones y posiciones de los militares que se mostrasen cercanas a los sectores que manifestasen oposición al Gobierno. Por ejemplo, en 1964 el general Alberto Ruiz Novoa escribió en la Revista de las Fuerzas Armadas las siguientes líneas: "No es difícil probar que en Colombia existe un estado de injusticia en torno a la posición de la tierra y que esta situación es la responsable de la pobreza y el atraso del país”. Esta posición en favor de una mejor distribución de la propiedad fue rechazada de plano por sectores que consideraron la acción del ministro como una intervención indebida en política, a su vez, altos oficiales, como el general Reveiz Pizarro, afirmaban que esta posición era favorable a los enemigos del entonces presidente Guillermo León Valencia (Blair, 1993, pp. 92-93). Hay que considerar que, en esta década, surgieron numerosas voces desde el Partido Liberal y la izquierda en favor de una reforma agraria, siguiendo los lineamientos de la Alianza para el Progreso, propuesta por John F. Kennedy, de ahí que la opinión del general suscitase tal polémica. 
De esta manera, el poder civil estableció como límite a las Fuerzas Armadas el manejo del orden público y no toleraba opiniones diferentes en las Fuerzas Militares hacia el Estado y sus políticas. Se puede afirmar que las Fuerzas Militares terminaron sometidas al sistema bipartidista, y, por medio de su función del manejo del orden público, entregaban una forma de legitimidad a la acción gubernamental. Sin embargo, esto produjo una situación paradójica, ya que, al someterse a los poderes establecidos, tanto los políticos como los económicos, las Fuerzas Armadas ganaron independencia en la ejecución de sus acciones y planes para el manejo del conflicto armado y el orden público.

\section{Los setenta: adopción de la Doctrina de Seguridad Nacional}

Las Fuerzas Militares colombianas, como ya se ha dicho, se adaptaron al funcionamiento del Frente Nacional, asumiendo como propia su defensa ante las diversas formas de oposición al mismo. De todos modos, no puede desconocerse el contexto internacional de la época, el cual estaba marcado por la Guerra Fría y la consecuente división ideológica por cuenta de la confrontación Este-Oeste. En tal sentido, hubo en las Fuerzas Armadas de los países latinoamericanos, en cierta medida, una influencia de la Doctrina de la Seguridad Nacional (DSN), un conjunto de normas establecidas por los Estados Unidos para el adoctrinamiento y capacitación de los militares latinoamericanos. Así, la doctrina establecía un frente común, liderado por Estados Unidos, contra el comunismo, el cual era visto como un enemigo que debía ser erradicado y que constituía una amenaza para la propia existencia de la sociedad. La responsabilidad en el combate contra ese adversario debía correr por cuenta de las Fuerzas Militares, las cuales, en el caso latinoamericano, se consideraban las únicas portadoras válidas de las nociones de patria y nación, por lo que personas con conceptos o pensamientos distintos a los de las Fuerzas Militares podían ser señalados como subversivos y debían ser combatidos.

La DSN pretendía, en alguna medida, evitar que surgiese una "nueva Cuba” en Latinoamérica, por ello, desde los Estados Unidos se impulsó la idea de que los Estados Latinoamericanos se encontraban en un "estado de guerra 
permanente", no solo contra las guerrillas, sino también contra un "enemigo interno", que no se encontraba claramente definido ni localizado, pero que tenía la capacidad para introducirse y camuflarse tras la población en el interior de la nación. Este enemigo era el comunismo internacional, al cual se acusaba de pretender, por medio de acciones subversivas, destruir el orden establecido. Cabe anotar que aunque la Unión Soviética había mantenido su política de "el socialismo en un solo país", los discursos del Che Guevara, en especial el denominado "Mensaje a la Tricontinental", en el que se llamaba a la insurrección mundial y al uso de la guerra irregular o de guerrillas como arma de guerra en el Tercer Mundo, serviría como pretexto para considerar como verdadera la existencia de tal amenaza, aunque el apoyo cubano a las guerrillas, salvo en Angola y Bolivia, fue muy limitado.

Por tanto, era necesario que las Fuerzas Armadas establecieran mecanismos para el combate contra los eventuales "focos de la subversión", los cuales se encontraban en los sectores de oposición tales como universidades, sindicatos y organizaciones sociales, así como movimientos políticos y grupos de religiosos. Así, los medios utilizados en el combate contra ese enemigo no solo se limitaban al combate antisubversivo, sino también al uso de métodos represivos contra los "focos de la subversión". De esta manera, surgieron los regímenes militares del Cono Sur que se caracterizaron por el uso de métodos que atentaban contra los derechos humanos con el pretexto de la defensa de la seguridad (García, 1995, pp. 35-45).

En términos generales, este es el panorama de la DSN para nuestra región; sin embargo, se debe considerar que, aunque esta tuvo influencia en los diversos estamentos castrenses latinoamericanos, su aplicación práctica tuvo diferencias de un país a otro. Los países del Cono Sur, como Argentina, Chile, Uruguay y Brasil, implementaron en forma total el modelo de la doctrina; en Colombia, en cambio, su implementación fue muy diferente, pues como ya se ha indicado, hubo una continuidad de las instituciones democráticas y no se llevó a cabo una toma del poder Ejecutivo o del control de alguna de las otras ramas del poder público por parte de los militares.

Como señala Francisco Leal Buitrago (1994, pp. 52-54), los militares colombianos construyeron su propia versión de la DSN a partir de sus propias 
interpretaciones. Así, el sector castrense construyó una concepción ideal de la DSN adaptada a las circunstancias internas, pero conservando la idea anticomunista, la cual era difundida en espacios como las publicaciones de las Fuerzas Armadas y la Escuela Superior de Guerra.

Como se ha visto, el panorama político de las décadas de los sesenta y setenta influyó en la configuración ideológica de las Fuerzas Militares colombianas, las cuales asumieron el manejo del orden público como su principal función. La que iba acompañada de un sometimiento al Estado y su sistema político, determinado por el Frente Nacional, cuyos gobiernos, en aras de defender su legitimidad contra las formas de oposición, otorgaron a las Fuerzas Armadas libertad para actuar. Así, los problemas que tenían razones políticas terminaron convertidos en asuntos de orden público y seguridad, este objetivo se lograba por medio de la política de estado de sitio. De esta manera, las Fuerzas Armadas consolidaron una autonomía en su función de guardianes del orden público, por lo que los diseños de estrategias para el control de la población fueron tarea exclusiva de los militares.

\section{Entre el Plan Lazo y el Estatuto de Seguridad}

Cabe anotar que dentro de las estrategias y planes de seguridad propuestos durante el Frente Nacional hubo dos visiones, una que puede considerarse "desarrollista” y cercana a las teorías de la Comisión Económica para América Latina y el Caribe (Cepal), y otra, de cuño propio, denominada Estatuto de Seguridad.

Según Aldo Ferrer (1998), la tendencia desarrollista consideraba que los problemas de la región se derivaban de la estructura de dependencia económica entre el mundo desarrollado (o también llamado centro), caracterizado por la producción de bienes con valor agregado (manufacturas) y el Tercer Mundo (también conocido como periferia), cuya producción económica estaba enfocada en materias primas (productos agrícolas y minerales sin valor agregado). Muchos de los planes de transformación económica o dirigidos a la búsqueda de un cambio estructural pretendían mejorar las condiciones de vida de la región, evitando una eventual influencia del comunismo. 
Estas propuestas económicas, impulsadas por iniciativas estadounidenses como la Alianza Para el Progreso, debían tener articulación con las políticas de seguridad y defensa estatales, dentro de las cuales la lucha contrainsurgente tenía un componente esencial. El presidente John F. Kennedy llegó a afirmar que:

La subversión es otro tipo de guerra, nuevo en su intensidad, aunque de antiguo origen [...]. Cuando debemos contrarrestar este tipo de guerra, estamos obligados a emplear una nueva estrategia, una fuerza militar diferente, lo que requiere una preparación y adiestramiento militar nuevos y distintos. (NCOS, 1995, p. 7)

El Plan Lazo fue una estrategia militar diseñada por el General Alberto Ruiz Novoa ${ }^{5}$, que buscaba una pacificación del país a largo plazo. El objetivo principal del plan era llevar a cabo una "acción cívico-militar" que, ante todo, pretendía invertir la relación de apoyo entre la guerrilla y el campesinado, o como el propio General Ruiz Novoa lo definió: "quitarle el agua al pez". Sin embargo, como señala Leal Buitrago (2002, pp. 43-44), el Plan estaba articulado con las teorías desarrollistas de W. W. Rostow. Dentro del Plan se incluían proyectos como procesos de alfabetización, construcción de infraestructura y atención en salud, orientadas por las Fuerzas Militares, con el objeto de ganarse el apoyo de la población. No obstante, aunque estos proyectos formaban parte de los componentes del Plan, en su ejecución terminaron primando las estrategias de guerra psicológica contra la subversión (Gallón, 1983, pp. 24-25). En este tipo de operaciones, el propósito se centraba en lograr la cooperación y el apoyo de la población civil, por medio de métodos de amenaza y, en ocasiones, de terror, que limitasen el potencial apoyo a la guerrilla.

5 El General Ruiz Novoa tuvo una ascendente carrera dentro de las Fuerzas Militares, después de su regreso de Corea, donde participó como uno de los comandantes del Batallón Colombia. Había sido funcionario de Rojas Pinilla, por lo que era consciente del contesto de la Guerra Fría, y el anticomunismo como política de Estado. Luego fue comandante del Ejército en el gobierno de Alberto Lleras, donde conservó un grado de autonomía en el desarrollo de políticas de seguridad, a pesar de lo cual mantuvo su posición en el respeto institucional, tal como Lleras lo había planteado en su discurso en el Teatro Patria, en el que abogaba por la no deliberación de los militares en los asuntos políticos. Si bien, el Plan Lazo fue propuesto en el gobierno Lleras, sería en el gobierno Valencia en el que Camacho Leiva fue ministro de Guerra (hoy, Defensa), fue donde empezaría a implementarse. 
Se puede afirmar que, a pesar su intención social, el Plan Lazo tenía un alto componente ideológico anticomunista, el cual se veía reforzado con las publicaciones del Ejército que hacían constante mención del comunismo como enemigo y la necesidad de contenerlo, siguiendo el ejemplo de las acciones militares en Malasia y Argelia, en las que los militares combinaban la acción cívica con el accionar militar directo. En el caso concreto malayo, la estrategia liderada por el Gobierno fue conocida como "mentes y corazones", en la que se buscaba aislar a las guerrillas de la población para hacer más eficiente la tarea del Estado. En tal sentido, se puso en marcha un programa de repoblamiento forzado y masivo de la población, por medio del cual se buscaba persuadir a esta de que era más conveniente apoyar al Gobierno que a los grupos armados irregulares $^{6}$ (Rangel, 1998). Tal intención de crear esa alianza entre civiles y militares estaba implícita en el Plan Lazo.

El nombre Lazo, venía de la idea de "enlazar" o llevar a cabo un cerco militar sobre las zonas con presencia guerrillera, lo cual se hizo patente en dos de los municipios que fueron considerados como "repúblicas independientes", como lo eran Marquetalia y Riochiquito, adelantando una operación militar de tierra arrasada para el primero, y operativos cívico-militares para el segundo, quellevarían al surgimiento de las FARC, descrito previamente (Molano, 2014). Si bien estos programas y su acción militar contra los enclaves comunistas fueron aplaudidos inicialmente por la opinión pública, como señala Eduardo Pizarro (2006), estas acciones terminaron siendo contraproducentes, porque entregarían a las FARC un mito fundacional, en la medida que se confundió el nombre "Lazo", con la propuesta de seguridad estadounidense denominada "Laso" que era la sigla de Latín American Security Operación, un plan contrainsurgente que, desde Washington, también promulgaba “Operaciones psicológicas" en la lucha contrainsurgente como una estrategia de tipo global, dentro

6 Como anota Rangel: "En Malasia, los insurgentes lograron conformar durante la ocupación japonesa un poderoso ejército y tomar una zona bajo control guerrillero. En el momento en que el gobierno declaró el Estado de Emergencia, luego de los intentos frustrados de los rebeldes para provocar una insurrección urbana y derrocar al gobierno, éste no tenía una evaluación objetiva de la fuerza real de las guerrillas ni de su apoyo entre la comunidad china. Las primeras medidas del Estado de Emergencia parecían más adecuadas para controlar los brotes de delincuencia organizada que en forma de bandas criminales aprovechaban el desorden de la postguerra, que para confrontar la amenaza político militar que representaba la insurgencia." 
de la cual se debía combatir el comunismo, lo que fue adoptado en numerosos manuales del Ejército colombiano.

La segunda estrategia notable consistió en el diseño del Estatuto de Seguridad, que tuvo lugar durante el gobierno de Julio César Turbay Ayala (1978-1982). El estatuto era un conjunto de normas y medidas de excepción, con las cuales el presidente esperaba llevar a cabo una lucha contra las mafias y guerrillas que generaban condiciones de inseguridad e inmoralidad, las cuales, consideraba el primer mandatario, constituían los factores que amenazaban al Estado (Torres del Río, 2000, p. 219). En la construcción de la normatividad establecida en el estatuto, tuvieron gran influencia las determinaciones del ministro de Defensa, el general Luis Carlos Camacho Leyva ${ }^{7}$. El ministro de gobierno de Turbay, Germán Zea Hernández manifestó que la seguridad fue el primer punto en la agenda presidencial, ya que esta materia era, según el ministro, una de las solicitudes que hizo la sociedad al presidente Turbay desde el inicio de su mandato (Alape, 1985, p. 379-380).

Como lo menciona Francisco Leal Buitrago (2002, p. 59), el Estatuto de Seguridad no buscaba aumentar la ya consolidada autonomía militar, sino, más bien, otorgar a las Fuerzas Armadas una serie de herramientas jurídicas para la lucha contra el narcotráfico y las guerrillas. El Estatuto estableció nuevas formas delictivas y aumentó las penas para delitos ya existentes, del mismo modo, permitía ejercer la censura sobre medios de comunicación tanto audiovisuales como escritos. Por ejemplo, un delito como la rebelión que antes del Estatuto tenía una pena de 6 a 4 años de prisión, pasó a condenas de entre 8 y 14 años.

El estatuto partía de dos factores: en primer lugar, se llevó a cabo una ampliación de la noción de "perturbador del orden público". Esta sindicación se hizo extensiva a una serie de actividades que antes eran juzgadas como simples contravenciones y que a partir del Estatuto se habían convertido en delitos (Gallón, 1983, p. 134). Según la legislación del Estatuto, las perturbaciones del orden público abarcaban conductas que "alteraran el pacífico desarrollo

7 Como señala Leal Buitrago (2002, p. 58), el General Camacho Leyva pertenecía a otra generación de militares que ya había dejado atrás la visión desarrollista y, por el contrario, sostenía la visión anticomunista que veía en la represión la única forma válida para enfrentar a los grupos insurgentes. 
de las actividades sociales o provo[caran] incendios y en tales circunstancias suprimieran la vida de las personas" (Rivas, 1980, p. 311). Sin embargo, estas definiciones, para analistas como Gustavo Gallón, eran muy vagas y permitían que cualquier actitud o situación que no fuese bien vista por el Gobierno podría ser juzgada como perturbación.

De esta manera, el Estatuto también amplió las connotaciones del concepto "subversivo", que llegó a cobijar actividades como pintar grafitis, distribuir propaganda, exhibir dibujos o textos contra el Gobierno en espacios públicos, y criminalizó las formas de huelga y protesta social, pues el Gobierno tenía la potestad de considerar que en ellas podía haber intención de derrocar al Gobierno, por lo que podía actuar con rigor y excesos, incluso contra aquellos que solo fuesen observadores de los sucesos. El segundo gran pilar del Estatuto de Seguridad fue la ampliación de las funciones de las Fuerzas Militares, que pasaron al ámbito judicial, por medio de la aplicación práctica de la Justicia Penal Militar para civiles. Mediante consejos de guerra, los militares adquirieron la capacidad para juzgar los delitos señalados previamente. También otros elementos de la Fuerza Pública, como el DAS y la Policía, llevaron a cabo juicios contra civiles. La capacidad judicial de las Fuerzas Militares muestra que en el país también se presentó una ocupación del Estado por parte de las Fuerzas Armadas (Reyes et al., 1978, p. 109).

Para Iván Orozco Abad (1992, pp. 171-172), el Estatuto de Seguridad fue el resultado de los sucesivos estados de excepción dirigidos contra la protesta social. Por tanto, aunque el Estatuto consideraba a los manifestantes como delincuentes políticos, las figuras criminales creadas por la legislación llevaba a que varias conductas que tenían conexión con el delito de rebelión terminaban asimiladas como delitos comunes. Estas circunstancias condujeron a que las víctimas de la legislación fuesen los movimientos políticos y sociales, pues sus acciones terminaron asimiladas como perturbaciones del orden público, las cuales, al ser establecidas como delitos, eran susceptibles de ser reprimidas.

Desde su promulgación, el Estatuto fue recibido con beneplácito por parte de los gremios y los sectores políticos dominantes, que consideraban que el modelo impuesto por las Fuerzas Militares garantizaba condiciones de seguridad contra los enemigos del Estado, a los que consideraban influidos por 
la guerrilla. Sin embargo, también comenzaron a surgir críticas de distintas organizaciones sociales, que harían patentes los abusos y arbitrariedades que se cometían por parte de los militares en su accionar. Esto fortalecería a los movimientos en pro de los derechos humanos y la búsqueda de una negociación política para resolver el conflicto.

\section{Conclusión}

Durante el Frente Nacional, las Fuerzas Armadas colombianas presentaron una dualidad en su estructura, pues, por un lado, se sometió a la institucionalidad y se buscó el acceso directo al control absoluto por parte de los poderes políticos. Tal sometimiento implicó que los militares no tuviesen posiciones críticas ante el orden socioeconómico, y las pocas intervenciones que hubo en este sentido fueron rechazadas por los sectores políticos civiles, que vieron en esas posiciones una indebida intromisión en política.

Por otro lado, de forma paralela al reconocimiento del poder de las autoridades civiles, los militares contaron con un alto grado de libertad y autonomía en el manejo del orden público. De esta manera se gestó un pacto no escrito entre el poder civil y el poder militar en Colombia, en el que los militares no intervendrían en los temas políticos, y en contraprestación los civiles se desentenderían del diseño de estrategias de seguridad, las cuales estarían en manos de los militares.

El periodo del Frente Nacional se caracterizó por la presencia de dos elementos claves. Por un lado, la puesta en práctica de forma constante del estado de sitio, facultad que podía declarar perturbado el orden público en determinado lugar o en la totalidad del territorio nacional, lo que justificaba que el Gobierno adquiriese poderes y atribuciones especiales para gobernar, sin contrapeso del Poder Legislativo o del Judicial. Muchas veces, el estado de sitio era proclamado en los momentos en que había reclamaciones ciudadanas, como huelgas laborales, campesinas y estudiantiles, las cuales, al ser consideradas como problemas de seguridad, podían ser combatidas con dureza. En el uso de esas facultades, los militares veían acrecentada su autonomía y llevaron a cabo acciones represivas con el pretexto de restaurar el orden. 
El segundo elemento que debe tomarse en consideración, es que en este mismo periodo surgieron los primeros grupos guerrilleros, los cuales intentaron emular la acción de la Revolución cubana, aunque no recibieron apoyo del bloque comunista. Las acciones de estos grupos sirvieron como pretexto a los militares para su accionar represivo. Con el desarrollo de los procesos de paz, se ha buscado una reformulación en el papel de las Fuerzas Armadas, para que pasen de tener el control del orden público a dedicar sus labores a la defensa y seguridad en las fronteras, lo que ayudaría a fortalecer la institucionalidad democrática.

\section{Referencias}

Alape, A. (1985). La paz, la violencia: testigos de excepción. Planeta.

Aramburo, J., \& Salamanca, A. (1981). El cuadro de la justicia. Estado de sitio sin estado de sitio. Revista controversia, (94), 9-122.

Blair, E. (1993). Las Fuerzas armadas. Una mirada civil. Cinep.

Ferrer, A. (1998). América Latina y la globalización. Revista de la Cepal, 155-168.

Gallón, G. (1979). Quince años de estado de sitio en Colombia 1958-1978. América Latina.

Gallón, G. (1983). La República de las armas. Relaciones entre Fuerzas Armadas y Estado en Colombia. Cinep.

García, P. (1995). El drama de la Autonomía Militar. Argentina bajo las juntas militares. Alianza.

Hartlyn, J. (1993). La Politica del régimen de coalición. La experiencia del Frente Nacional en Colombia. Tercer Mundo Editores, 99-101.

Leal, F. (1994). El oficio de la guerra. La seguridad nacional en Colombia. Tercer Mundo.

Leal, F. (2002). La seguridad nacional a la deriva. Del Frente Nacional a la Posguerra Fría. Alfaomega.

Molano, A. (2014). Asalto a Marquetalia. El Espectador. https://www.elespectador.com/noticias/ nacional/asalto-a-marquetalia/

NCOS. (1995). Tras los pasos perdidos de la guerra sucia. Paramilitarismo y operaciones encubiertas en Colombia. NCOS.

Orozco, I. (1992). Combatientes rebeldes y terroristas. Guerra y derecho en Colombia. Temis.

Palacios, M. (2000). Entre la legitimidad y la violencia: Colombia 1875-1994. Norma.

Palacios, M. (2012). Violencia pública en Colombia, 1958-2010. Fondo de Cultura Económica.

Pécaut, D. (1989). Crónica de dos décadas de politica colombiana 1968-1988. Siglo XXI.

Pizarro, E. (1989). "La Guerrilla y el proceso de paz”. En G. Gallón (Ed.), Entre movimientos y caudillos. 50 años de bipartidismo, izquierda y alternativas populares en Colombia (pp. 247-260). Cerec. 
Pizarro, E. (2004). Una democracia asediada balance y perspectivas del conflicto armado en Colombia. Norma.

Pizarro, E. (2006). Marquetalia: el mito fundacional de las Farc. UN Periódico. http://historico. unperiodico.unal.edu.co/ediciones/57/03.htm

Rangel, A. (1998). Nuestra guerra y otras guerras. Revista de Estudios Sociales, (2), 1-17.

Reyes, A., Hoyos, G., \& Heredia, J. (1978). Estatuto de Seguridad. Seguridad nacional, Derechos Humanos, Democracia restringida. Revista controversia, (70-71),

Rivas, G. (1980). Libro negro de la represión 1958-1980. Fica. Fundación para la Investigación y la Cultura.

Rouquié, A. (1984). El Estado militar en América Latina. Siglo XXI.

Rouquié, A., \& Saffern, F. (1997). Los militares en la política latinoamericana desde 1930. En L. Bethell, Historia de América Latina 12. Política y sociedad desde 1930 (pp. 281-341). Crítica.

Torres del Río, C. (2000). Fuerzas Armadas y Seguridad Nacional. Planeta.

Weber, M. (1964). Economía y Sociedad (Vol. II). Fondo de Cultura Económica. 